\title{
Factors Determining the Clinical Complications of Radiosurgery for AVM
}

\author{
Matylda Machnowska, Patamintita Taeshineetanakul, Sasikhan Geibprasert, \\ Ravi Menezes, Ronit Agid, Karel G. Terbrugge, Yuri Andrade-Souza, \\ Michael L. Schwartz, Timo Krings
}

\begin{abstract}
Purpose: To identify the predictors of symptomatic post-radiation T2 signal change in patients with arteriovenous malformations (AVM) treated with radiosurgery. Materials and Methods: The charts of 211 consecutive patients with arteriovenous malformations treated with either gamma knife radisurgery or linear accelerator radiosurgery between 2000-2009 were retrospectively reviewed. 168 patients had a minimum of 12 months of clinical and radiologic follow-up following the procedure and complete dosage data. Pretreatment characteristics and dosimetric variables were analyzed to identify predictors of adverse radiation effects. Results: 141 patients had no clinical symptomatic complications. 21 patients had global or focal neurological deficits attributed to symptomatic edema. Variables associated with development of symptomatic edema included a non-hemorrhagic symptomatic presentation compared to presentation with hemorrhage, $\mathrm{p}=0.001$; OR $(95 \% \mathrm{CI})=6.26(1.99,19.69)$; the presence of venous rerouting compared to the lack of venous rerouting, $\mathrm{p}=0.031$; OR $(95 \% \mathrm{CI})=3.25(1.20,8.80)$; radiosurgery with $\mathrm{GKS}$ compared to linear accelerator radiosurgery $\mathrm{p}=$ 0.012 ; OR $(95 \% \mathrm{CI})=4.58(1.28,16.32)$; and the presence of more than one draining vein compared to a single draining vein $\mathrm{p}=0.032$; OR $(95 \% \mathrm{CI})=2.82(1.06,7.50)$. Conclusions: We postulated that the higher maximal doses used with gamma knife radiosurgery may be responsible for the greater number of adverse radiation effects with this modality compared to linear accelerator radiosurgery. We found that AVMs with greater venous complexity and therefore instability resulted in more adverse treatment outcomes, suggesting that AVM angioarchitecture should be considered when making treatment decisions.
\end{abstract}

RÉSUMÉ: Facteurs en cause dans les complications cliniques de la radiochirurgie pour une malformation artérioveineuse. Objectif : Le but de l'étude était d'identifier les facteurs de prédiction de changement du signal T2 qui sont symptomatiques après l'irradiation chez des patients présentant une malformation artérioveineuse (MAV) traitée par radiochirurgie. Méthode : Les dossiers de 211 patients consécutifs atteints d'une MAV, qui ont été traités soit par radiochirurgie par scalpel gamma ou par radiochirurgie par accélérateur linéaire entre 2000 et 2009, ont été examinés rétrospectivement. Un suivi clinique et radiologique d'au moins 12 mois après le traitement était disponible ainsi que des données complètes sur la dose administrée chez 168 patients. Les caractéristiques avant le traitement et les variables dosimétriques ont été analysées pour identifier les facteurs de prédiction d'effets indésirables de l'irradiation. Résultats : Cent quarante et un patients n'ont pas présenté de complication symptomatique au point de vue clinique. Vingt et un patients ont présenté des déficits neurologiques globaux ou focaux attribués à un œdème symptomatique. L'une des variables associées à un œdème symptomatique était une symptomatologie non reliée à une hémorragie au moment de la consultation initiale par rapport une symptomatologie reliée à la présence d'une hémorragie $(\mathrm{p}=0,001), \mathrm{RC}=6,26 ; \mathrm{IC}$ à $95 \%:(1,99$ à 19,69); la présence de déviation de la circulation veineuse par rapport à son absence $(\mathrm{p}=0,031 ; \mathrm{RC}=3,25 ;$ IC à $95 \%: 1,20$ à 8,80); la radiochirurgie par scalpel gamma par rapport à la radiochirurgie par accélérateur linéaire $(\mathrm{p}=0,012 ; \mathrm{RC} 95 \%=4,58 ; \mathrm{IC}$ à $95 \%: 1,28$ à 16,32); et la présence de plus d'une veine de drainage par rapport à la présence d'une seule veine de drainage ( $\mathrm{p}=0,032 ; \mathrm{RC}=2,82 ; \mathrm{IC}$ à $95 \%$ 1,06 à 7,50). Conclusions : Nous avons émis l'hypothèse que les doses maximales plus élevées utilisées lors de la radiochirurgie par scalpel gamma pourraient être responsables du plus grand nombre d'incidents thérapeutiques dus à l'irradiation par rapport à la radiochirurgie par accélérateur linéaire. Nous avons observé de moins bons résultats du traitement des MAV possédant une plus grande complexité veineuse et donc une plus grande instabilité, ce qui suggère que l'architecture des vaisseaux d'une MAV devrait être prise en considération lorsque du choix du traitement.

Can J Neurol Sci. 2013; 40: 807-813

Arteriovenous malformations (AVMs) are complex intracranial vascular malformations accounting approximately for $2 \%$ of all strokes due to a $2-5 \%$ annual risk of hemorrhage mostly in patients between 20 and 40 years-of-age. ${ }^{1,2}$ Their pathogenesis remains poorly understood. Studies have shown the up regulation of over 300 genes and down regulation of almost 560 genes, responsible for encoding growth factors, cell adhesion factors, inflammatory factors and endocrine hormones. ${ }^{3}$ The expression of these factors is contributed to by the local environment, and in particular regional hypoxia, which in turn is affected by AVM angioarchitecture and treatment choice. $^{4}$

From the Division of Neuroradiology, Department of Medical Imaging (MM, PT, SG, RM, RA, KGT, TK), Division of Neurosurgery (YAS, MLS), Toronto Western Hospital, Toronto, Ontario, Canada.

Received March 20, 2013. Final Revisions Submitted July 4, 2013. Correspondence to: M. Machnowska, University of Toronto, Toronto Western Hospital, UHN, Division of Neuroradiology, 399 Bathurst St., 3MCL - 429, Toronto, Ontario, M5T 2S8, Canada. Email: mmachnowska@gmail.com. 
Radiosurgery has been used as a treatment for AVMs for almost four decades ${ }^{5}$, and has been shown to have low complication rates and rather high rates of obliteration. Flickinger and Pollock devised a grading scheme for selecting gamma knife radiosurgery (GKS) patients based on the association of pretreatment factors with post radiotherapy obliteration and complications. ${ }^{6}$ This scale was validated for use with linear accelerator (LINAC) radiosurgery by Andrade-Souza et al. in $2005,{ }^{7}$ and simplified by Pollock et al in $2008 .^{8}$ Factors considered significant included AVM volume, patient age, AVM location, prior embolization, and number of draining veins. ${ }^{6}$

Post treatment complications have been stratified into immediate effects such as increased risk of seizure in patients with cortical lobar AVMs, post-radiosurgery imaging changes, hemorrhage and late complications including persistent edema, radiation necrosis, radiation induced tumours and cyst formation. In the literature there is some confusion regarding "imaging complications" and "clinical complications;' for the purposes of this study we have elected to look only at clinically symptomatic post-radiosurgery imaging changes. In several past studies, symptomatic changes have been found to occur in approximately $3-17 \%$ of patients. ${ }^{5-15}$ This variation may be related to the definition of complications.

Several studies have looked at complication rates in relation to AVM variables and treatment related variables, however most studies have not looked at the specific angioarchitecture of AVMs in relation to the occurrence of complications..$^{10,16-25}$

Angioarchitecture may however be an important determining factor for complications following radiosurgery. For example, there is an increased rate of post-radiation imaging changes in radiosurgically treated AVMs as compared to neoplasms, one study showing the incidence to be $31 \%$ in the former and $8 \%$ in the latter. ${ }^{16} \mathrm{~A}$ proposed explanation for this phenomenon is that of occlusive hyperemia ${ }^{26}$, resulting from an imbalance of arterial inflow and venous outflow due to progressive venous occlusion in a high flow lesion. Given these considerations one may hypothesize that high flow AVMs are more prone to treatment complications. In the same line of thought, one may hypothesize that AVMs with signs of venous outflow obstruction on pre radiosurgical scans may also be more prone to symptomatic complications as it has been shown that a single draining increases the risk of hemorrhage. ${ }^{27}$ Venous outflow obstruction leads to rerouting of arterialized blood into veins that normally drain the brain and therefore interfere with function of the brain remote from the shunt. Arteriovenous malformations with venous rerouting or venous obstruction may have a higher rate of symptomatic complications, because of the unstable hemodynamics surrounding these lesions.

The aim of this study was, therefore to correlate the occurrence of symptomatic complications with preradiotherapeutical angioarchitectural features.

\section{Material AND Methods}

Following University Health Network research ethics board approval, a retrospective review of 211 consecutive brain arteriovenous malformation (BAVM) patients who underwent GKS at the Toronto Western Hospital, or LINAC radiosurgery at Sunnybrook Health Sciences Centre between 2000 and 2009 was performed. Patients were first clinically seen at three months, then six months and then at yearly intervals. Magnetic resonance imaging (MRI) was performed at the first 6 months, 12 months and then annually. Thirty-three patients who were either lost to follow-up or had a follow-up of less than 12 months, were excluded from the subsequent analyses. The medical charts and imaging studies of the remaining 178 patients were reviewed for patient demographics, BAVM angioarchitecture, and the
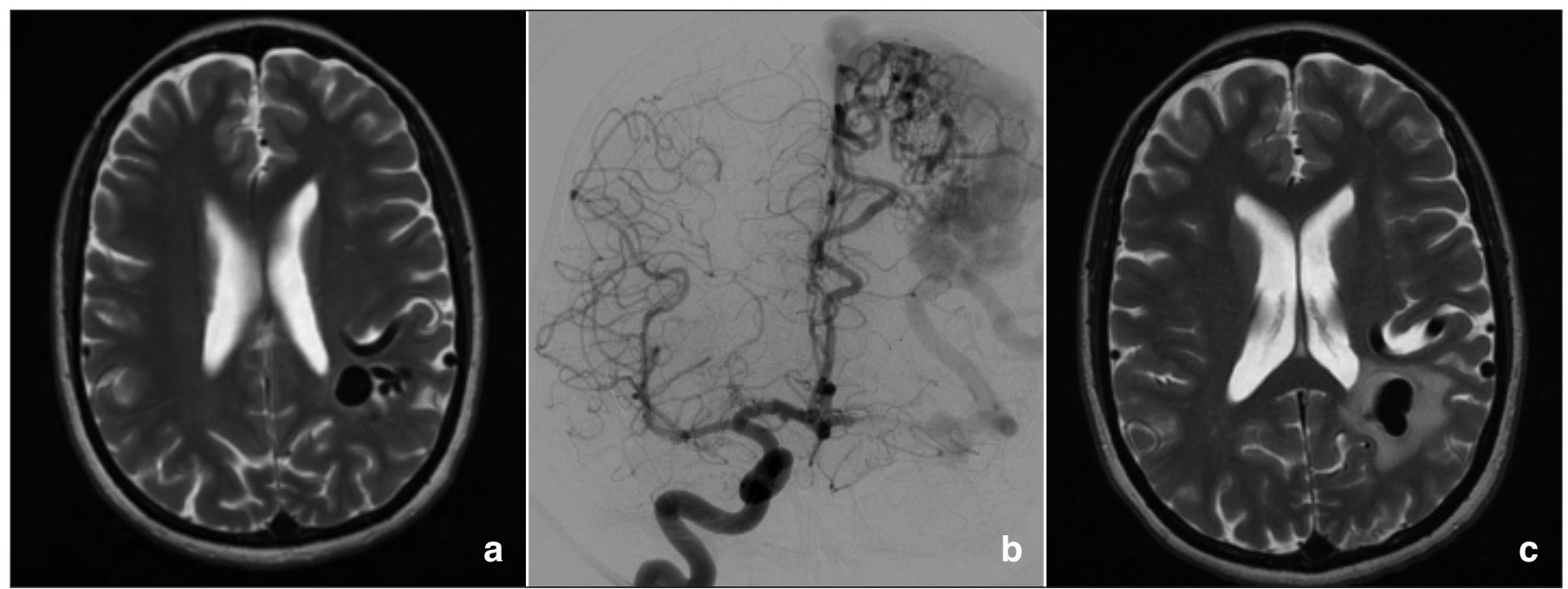

Figure: Left parietal AVM in 49-year-old female who presented with tinnitus: a. Axial T2 weighted MRI at the time of diagnosis shows the presence of a venous pouch and venous ectasia, $b$. Right internal carotid angiogram performed prior to treatment shows enlarged left anterior cerebral artery branches feeding the predominantly left middle cerebral artery territory AVM. Arterial enlargement and perinidal angiogenesis are present. There was both deep and superficial AVM drainage, with evidence of venous rerouting, but no pseudophlebitic pattern. c. Axial T2 weighted MRI performed 35 months following treatment with GKS shows a region of T2 hyperintensity in the left parietal lobe. The patient presented four months following GKS with right hand numbness, and increasing headaches with sharp pains in the left parietal lobe. 
radiosurgical procedure received as detailed below. Complete dosage data was available for 168 of these 178 patients; none of the ten patients for whom dosage data was not available had experienced complications.

The methods used for digital subtraction angiography (DSA) and the radiosurgical procedure have been previously described elsewhere. ${ }^{28}$ They are described in brief below.

\section{Digital Subtraction Angiography}

In addition to cross-sectional imaging for treatment planning, all patients underwent simultaneous biplanar DSA prior to the radiosurgery as a part of the treatment planning. Image frame rate was standardized with a rate of three frames per second with injector controlled contrast injection rates of $4 \mathrm{cc} / \mathrm{sec}$ for a total of $8 c c$. All DSAs included early arterial to late venous phases.

The DSA images were evaluated for angioarchitectural details as follows: on the arterial side for feeding artery enlargement, and perinidal angiogenesis (Figure b) ${ }^{28}$ Arterial enlargement was categorized into no or mild enlargement if the feeding artery was of the same size or only slightly more prominent than the contralateral vessel and moderate-to-severe enlargement, if the arterial feeder was significantly larger $(>1.5 x)$ than the contralateral vessel or proximal parent artery.

The nidus was evaluated for the volumetric size (as determined from the original radiation plan based on crosssectional imaging), location (eloquent vs non-eloquent), nidus type (compact or diffuse) and flow pattern. We used the arteriovenous transit-time for evaluation of the BAVM flow pattern. This was estimated by determining the number of DSA frames in between first depiction of the nidus and first visualization of a vein. A high flow lesion was indicated if the venous drainage was promptly seen with the BAVM nidus or arterial feeders. If there were one frame difference from visualization of the nidus and draining vein, it was categorized as a moderate flow pattern and if the venous drainage was seen in two or more frames after nidal visualization, the BAVM was classified as a low flow lesion.

The venous system was evaluated for generalized venous ectasia (in relationship to the normal veins), the presence of venous pouches (focal enlargement), the drainage pattern (superficial vs deep), the number of draining veins, venous rerouting, and the presence of a so-called pseudophlebitic pattern which was defined as corkscrew-like dilated veins draining normal brain parenchyma in the late venous phase. The studies were read in consensus by two neuroradiologists (P.T and S.G) with 6 and 12 years of experience in angiography respectively.

\section{Radiosurgical procedure}

Radiosurgery was delivered using a 6-MV LINAC system (28-30) and a 4C GKS system. For LINAC-based radiosurgery, an Olivier-Bertrand-Tipal stereotactic frame was applied to the patient's head under local anesthesia. Patients subsequently underwent a contrast enhanced cross-sectional imaging computed tomogram (CT) of the brain, followed by stereotactic angiography. The images were transferred to the radiosurgery software. With very few exceptions, the prescription dose was 15- 20 Gy depending on the eloquence of AVM location, with non-eloquent location AVMs receiving 20 Gy at the $90 \%$ isodose contour and eloquent location AVMs receiving 15 Gy at the $67 \%$ isodose contour. The AVM volume was calculated using the best fit isodose method. The target definition, isocenter localization, and dose planning were performed by the same senior neurosurgeon in close collaboration with neuroradiology, radiation oncology and a physicist. For gamma knife radiosurgery, $\mathrm{CT}$ and MRI scanning and stereotactic angiography were all done and the prescription dose was $25 \mathrm{~Gy}$, usually at the $50 \%$ isodose contour for AVMs less than $4 \mathrm{cc}$ volume, 20Gy at the $50 \%$ isodose contour for AVMs larger than $4 \mathrm{cc}$ volume. The radiation exposure to eloquent brain adjacent to AVMs was limited to $15 \mathrm{~Gy}$. Ninety-six patients described herein received GKS and 72 patients had LINAC radiosurgery.

\section{Statistical Analysis}

Univariate tests (two-sided t-tests for continuous, normally distributed variables; Chi-squared and Fisher's exact tests for categorical variables) were used to evaluate the association of individual predictors with the development of focal neurological deficits, not due to arterial ischemia, hemorrhage or radiation necrosis. Predictors analyzed included the following: age, sex, AVM size, dose, flow pattern, nidus type, drainage type, number

Table 1: Dosage characteristics of LINAC versus GKS radiosurgery treatments

\begin{tabular}{|c|c|c|}
\hline Variable & LINAC & GKS \\
\hline \multicolumn{3}{|l|}{ Prescription Dose (Gy) } \\
\hline Mean & 17.5 & 19.9 \\
\hline Median & 15 & 20 \\
\hline Range & 12,25 & 15,25 \\
\hline \multicolumn{3}{|l|}{ Isocenter No. } \\
\hline Mean & 1.5 & 10.4 \\
\hline Median & 1 & 10.5 \\
\hline Range & 1,3 & 1,27 \\
\hline \multicolumn{3}{|l|}{ \% Isodose Contour* } \\
\hline Mean & 77.2 & 48.2 \\
\hline Median & 67 & 50 \\
\hline Range & 50,90 & 35,70 \\
\hline \multicolumn{3}{|l|}{ Treated Volume $\left(\mathrm{cm}^{3}\right)$} \\
\hline Mean & 5.1 & 3.8 \\
\hline Median & 3.0 & 2.2 \\
\hline Range & $0.17,21$ & $0.08,14.58$ \\
\hline \multicolumn{3}{|l|}{ Location } \\
\hline Eloquent (\%) & 73.6 & 70.8 \\
\hline Superficial (vs. deep or mixed) (\%) & 51.4 & 51.0 \\
\hline \multicolumn{3}{|l|}{ Age } \\
\hline Mean & 35 & 37 \\
\hline Median & 33 & 36 \\
\hline Range & 6,67 & 6,74 \\
\hline \multicolumn{3}{|l|}{ Angiographic Variables } \\
\hline Venous rerouting present $(\%)$ & 16.7 & 22.9 \\
\hline PPP *(\%) & 12.5 & 11.5 \\
\hline $\begin{array}{r}\text { Moderate to severe arterial } \\
\text { enlargment }(\%)\end{array}$ & 50 & 28 \\
\hline
\end{tabular}

Isodose Contour: A diagram of dose measurements or calculations where points of equal dose are connected so that the pattern of radiation dose can be understood and evaluated. PPP: Pseudophlebitic pattern 
Table 2: $\mathbf{P}$ values from a univariate analysis of the different variables investigated when comparing those patients who experienced no complication following radiosurgery to those experiencing symptomatic edema

\begin{tabular}{|c|c|c|c|c|}
\hline Variable & No complication ( $n=141)$ & Edema $(n=20)$ & p-value & OR $(95 \% \mathrm{Cl})$ \\
\hline \multicolumn{5}{|l|}{ Dose } \\
\hline Mean & 19 & 17.5 & 0.121 & \\
\hline Median & 20 & 15 & & \\
\hline SD & 3.83 & 3.72 & & \\
\hline range & 15,25 & 12,25 & & \\
\hline \multicolumn{5}{|l|}{ Age } \\
\hline Mean & 35.1 & 39.6 & 0.090 & \\
\hline Median & 32 & 38.5 & & \\
\hline SD & 15.94 & 10.97 & & \\
\hline range & 6,74 & 20,63 & & \\
\hline \multicolumn{5}{|l|}{ Size } \\
\hline$<3$ & $123(87 \%)$ & $15(75 \%)$ & 0.169 & \\
\hline $3+$ & $18(13 \%)$ & $5(25 \%)$ & & \\
\hline \multicolumn{5}{|l|}{ Flow } \\
\hline low & $61(43 \%)$ & $5(25 \%)$ & 0.120 & \\
\hline $\mathrm{mod} / \mathrm{high}$ & $80(57 \%)$ & $15(75 \%)$ & & \\
\hline \multicolumn{5}{|l|}{ Nidus type } \\
\hline Compact & $68(48 \%)$ & $7(35 \%)$ & 0.267 & \\
\hline Diffuse & $73(52 \%)$ & $13(75 \%)$ & & \\
\hline \multicolumn{5}{|l|}{ Drainage type } \\
\hline Superficial & $72(51 \%)$ & $7(35 \%)$ & 0.179 & \\
\hline Deep/mixed & $69(49 \%)$ & $13(65 \%)$ & & \\
\hline \multicolumn{5}{|l|}{ Drainage number } \\
\hline 1 vein & $85(60 \%)$ & $7(35 \%)$ & 0.032 & 1.00 \\
\hline$>1$ vein & $56(40 \%)$ & $13(65 \%)$ & & $2.82(1.06,7.50)$ \\
\hline \multicolumn{5}{|l|}{ Focal venous pouch } \\
\hline No & $110(78 \%)$ & $13(65 \%)$ & 0.258 & \\
\hline Yes & $31(22 \%)$ & $7(35 \%)$ & & \\
\hline \multicolumn{5}{|l|}{ Venous rerouting } \\
\hline No & $117(83 \%)$ & $12(60 \%)$ & 0.031 & 1.00 \\
\hline Yes & $24(17 \%)$ & $8(40 \%)$ & & $3.25(1.20,8.80)$ \\
\hline \multicolumn{5}{|l|}{ PPP } \\
\hline No & $126(89 \%)$ & $15(75 \%)$ & 0.079 & \\
\hline Yes & $15(11 \%)$ & $5(25 \%)$ & & \\
\hline \multicolumn{5}{|l|}{ Previous treatment } \\
\hline No & $105(75 \%)$ & $14(70 \%)$ & 0.670 & \\
\hline Yes & $36(26 \%)$ & $6(30 \%)$ & & \\
\hline \multicolumn{5}{|l|}{ Type } \\
\hline Linac & $63(45 \%)$ & $3(15 \%)$ & 0.012 & 1.00 \\
\hline Gamma knife & $78(55 \%)$ & $17(85 \%)$ & & $4.58(1.28,16.32)$ \\
\hline \multicolumn{5}{|l|}{ Dominant feeders } \\
\hline 0 or 1 & $107(76 \%)$ & $14(70 \%)$ & 0.585 & \\
\hline $2+$ & $34(24 \%)$ & $6(30 \%)$ & & \\
\hline \multicolumn{5}{|l|}{ Arterial enlargement } \\
\hline No/mild & $93(66 \%)$ & $9(45 \%)$ & 0.069 & \\
\hline Moderate/severe & $48(34 \%)$ & $11(55 \%)$ & & \\
\hline \multicolumn{5}{|l|}{ Nonsprouting angiogenesis } \\
\hline No & $113(80 \%)$ & $13(65 \%)$ & 0.148 & \\
\hline Yes & $28(20 \%)$ & $7(35 \%)$ & & \\
\hline \multicolumn{5}{|l|}{ Sprouting angiogenesis } \\
\hline No & $99(70 \%)$ & $13(65 \%)$ & 0.635 & \\
\hline Yes & $42(30 \%)$ & $7(35 \%)$ & & \\
\hline \multicolumn{5}{|l|}{ Eloquence } \\
\hline No & $43(31 \%)$ & $3(15 \%)$ & 0.151 & \\
\hline Yes & $98(70 \%)$ & $17(85 \%)$ & & \\
\hline 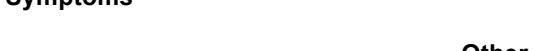 & & & & $6.26(1.99$, \\
\hline Other & $55(39 \%)$ & $16(80 \%)$ & 0.001 & 19.69) \\
\hline Hemorrhage & $86(61 \%)$ & $4(20 \%)$ & & 1.00 \\
\hline
\end{tabular}

$\mathrm{P}$ values from a univariate analysis of the different variables investigated when comparing those patients who experienced no complication following radiosurgery to those experiencing symptomatic edema. Odds ratios were calculated only for variables that showed statistical significance $(\mathrm{p}<0.05$ ) in a univariate analysis. $\mathrm{SD}=$ standard deviation 
of initially draining veins, eloquence, focal venous pouch, venous rerouting, pseudophlebitic pattern, prior treatment and type of radiosurgery. A p-value of $<0.05$ was considered statistically significant. For those predictors found to be statistically significant on univariate analysis, odds ratios (OR) were determined to reflect the magnitude of the association between each predictor and the outcome of interest. Finally, a multivariable logistic regression model was created utilizing the two most significant predictors on univariate analysis, in order to determine the independent effects of these predictors on the outcome. The number of predictors included in the model was limited to two on the basis of sample size considerations.

\section{Results}

Of the 168 patients analyzed, 27 (16\%) had clinical symptomatic complications on follow-up. Twenty $(11.9 \%)$ patients had global or focal neurological deficits attributed to symptomatic edema (Figure); four (2.4\%) patients had a hemorrhagic complication; two (1.2\%) patients had arterial ischemia, one in the region of the AVM and the other remote from the AVM; one $(0.6 \%)$ patient had radiation necrosis diagnosed as a result of persisting hearing loss of the right ear, sensory abnormalities in the right arm and right leg and coordination problems. Focal and global neurological deficits attributed to symptomatic edema included worsening of headaches; visual symptoms such as progressive loss of vision, homonymous quadrantanopsia and double vision; increased seizure frequency or transient worsening of seizure activity, motor and sensory symptoms involving the limbs and face (Figure). The range of symptom onset was between 1 and 66 months with mean and median presentation times of 12.9 and 10 months respectively. Thirteen patients presented within the first year of treatment and 19 patients within the first two years. Two patients initially presented with symptoms occurring in the first year following treatment, one presenting with episodic numbness in the right arm and the other with headache and visual loss, and acquired fixed deficits at 48 and 16 months respectively. The onset of the latter symptoms was excluded from calculation of the presentation times. The follow-up time ranged from 12 to 120 months. The mean and median follow-up times were 35.3 and 36 months respectively; 138 patients were followed up for at least 24 months. Treatment dosage data for patients treated both with LINAC and GKS are included in Table 1.

Univariate analysis demonstrated that predictors significantly associated with the development of symptomatic edema included asymptomatic or non-hemorrhagic presentation $(\mathrm{p}=0.001$; OR $(95 \% \mathrm{CI})=6.26(1.99,19.69))$, the presence of venous rerouting $(\mathrm{p}=0.031$; OR $(95 \% \mathrm{CI})=3.25(1.20,8.80))$; radiosurgery with GKS $(\mathrm{p}=0.012$; OR $(95 \% \mathrm{CI})=4.58(1.28,16.32))$; and the presence of more than one draining vein $(\mathrm{p}=0.032$; OR $(95 \%$ CI) $=2.82(1.06,7.50))$.

We found that gender, AVM size, flow rate through the AVM, the number of dominant feeders, perinidal angiogenesis, nidus type, drainage pattern, focal venous pouches, and eloquence were not significantly associated with the presence of symptoms. A few factors, including older age, the presence of moderate to severe arterial enlargement and the presence of a pseudophlebitic pattern approached statistical significance with $\mathrm{p}$ values of less than 0.1 . (Table 2)
No statistically significant angioarchitectural variables were found for the development of hemorrhagic complications, ischemia or radiation necrosis, likely related to the small number of afflicted patients. However, all of the patients with hemorrhagic complications had AVMs that drained through a single draining vein.

Multivariable logistic regression analysis was performed to determine the independent effects of presentation (asymptomatic or non-hemorrhagic versus hemorrhagic presentation) and radiosurgery type on the development of symptomatic edema post-radiosurgery. Both factors remained statistically significant predictors of outcome when adjusting for the other predictor in the model (asymptomatic or non-hemorrhagic presentation: $\mathrm{OR}(95 \% \mathrm{CI})=7.60(2.34,24.65) ; \mathrm{GKS}: \mathrm{OR}(95 \% \mathrm{CI})=5.89$ $(1.59,21.90))$.

\section{Discussion}

The statistically significant variables in our study associated with symptomatic post-radiation T2 signal change (edema) included the following: AVM drainage by more than one vein, lack of hemorrhage at presentation, GKS rather than LINAC radiosurgery and the presence of venous rerouting. The important angioarchitectural variables that have predicted adverse radiation effects in prior studies have included the number of draining veins, volume, and location..$^{8-10,29}$ In addition, Nataf et al found statistically significant higher rates of grade IV radiation induced changes (T2 signal abnormality and contrast enhancement) in those patients with arterial steal and those without exclusively deep venous drainage. ${ }^{21}$

Van den Berg et al showed a correlation that draining of an AVM through a single vein had a positive affect on obliteration rate and the development of white matter T2 hyperintensity. ${ }^{29}$ Pollock has suggested a venous occlusive cause responsible for the development of T2 signal abnormalities in two patients. ${ }^{26}$ Our findings that AVMs with greater than one draining vein had a higher chance of presenting with post-surgical symptomatic edema, would therefore seem contradictory to these papers. However, as recently pointed out by Hayhurst et al, who showed no statistically significant effect in AVM drainage through a single vein and symptomatic adverse radiation effects, the previously mentioned papers looked only at imaging abnormalities and not clinically symptomatic lesions. ${ }^{24}$ In addition, at least in untreated AVMs, the presence of greater than three draining veins was recently shown to result in more nonhemorrhagic neurological deficits. ${ }^{30}$ We would also like to note that in the original data compiled to create the Pollock and Flickinger grading system, the presence of more than one draining vein, had an inverse correlation with excellent patient outcomes, and was included in the full regression analysis model with AVM volume, patient age, location of lesion and previous embolization. ${ }^{6}$ However, because the R2 coefficient of this model displayed only minimal improvement over the best threevariable model, the latter has been accepted and subsequently verified in numerous studies. . $^{5,12,13,31}$

A possible cause of increased symptomatic edema with a greater number of draining veins may result from the overestimation of the size of the arteriovenous malformation during treatment planning. Although great care is taken to include only the arterial nidus in treatment planning, draining 
veins may rarely be included, particularly in the cases of high flow shunts where venous drainage is seen in the first frame of angiography. We believe, however, that this overestimation is a very rare event.

In this study significantly more patients treated with GKS had suffered symptomatic non-hemorrhagic adverse radiation effects as compared to patients treated by LINAC. Four percent of those treated with LINAC had exhibited symptomatic edematous changes compared to $17.7 \%$ of those treated with GKS. The cohorts did not significantly differ in the number of draining veins, presence of venous rerouting, presence of the pseudophlebitic pattern, or patient age. They did however differ in the number of isocenters, which has been shown to be a predictor of adverse radiation effects with GKS. ${ }^{24}$ In addition the average \% isodose contour in our GK cases was $50 \%$ for prescription doses of $20 \mathrm{~Gy}$ or $25 \mathrm{~Gy}$, while in LINAC cases it was either $67 \%$ for a prescription dose of $15 \mathrm{~Gy}$ and $90 \%$ for a prescription dose of $20 \mathrm{~Gy}$. The maximum dose to the AVM was, therefore, 22Gy, exclusive of "hot spots". The hot spots never exceeded $25 \mathrm{~Gy}$. Therefore the maximum doses in the cases of LINAC were $25 \mathrm{~Gy}$, while maximal doses in GK patients reached up to $50 \mathrm{~Gy}$, that is twice the prescription dose of 25Gy. Izawa and colleagues found an association between higher maximal treatment dose and delayed cyst formation, suggesting that it is associated with radiation injury. ${ }^{32}$ We conclude from the current study that increased maximal dose may also contribute to acute symptomatic edema. While Orio and colleagues found no difference in the rate of chronic radiation toxicity between AVM patients treated at their institution with LINAC and GKS, toxicity rates for the two modalities have varied somewhat in the literature: LINAC (5-17\%) and GKS (3-15\%). 5-7,13-15,33

The presence of prior hemorrhage has also been shown as a predictor of fewer post treatment complications in several studies. ${ }^{24,34}$ The reasons for this finding remain unclear. Possible explanations include postulations that hemorrhage results in destruction of neuronal tissue around the AVM causing gliosis. This gliotic tissue may show greater radioresistance. ${ }^{34}$ Several studies have implicated abnormalities in venous drainage such as venous hypertension, venous stenosis, a smaller number of draining veins and turbulent flow leading to thrombosis as factors that predispose to spontaneous AVM hemorrhage. ${ }^{27,35-38}$ Therefore, we postulate that patients who present with hemorrhage may have already experienced the insult that otherwise may occur from the presence of venous congestion following radiosurgery.

Finally, we feel the most significant findings of this study were that the presence of venous rerouting was associated with more symptomatic edema. The presence of venous rerouting suggests impaired venous outflow, and the development of venous collateral circulation that may also drain adjacent normal brain resulting in venous congestion in this territory. ${ }^{39}$ Two other variables that suggest AVM angioarchitectural complexity and therefore AVM instability, the presence of a pseudophlebitic pattern and the presence of moderate to severe arterial enlargement, approached significance and may have been significant in a larger cohort.

We feel ours is the only study to have looked at the angioarchitecture of treated AVMs in such detail, and suggest that consideration of AVM architecture should also be considered when making treatment decisions. An interesting, and unexpected, finding that has come from the comparison of our LINAC and GKS patient cohort, is that there was a significant association between the development of symptomatic adverse edema and treatment with GKS. We postulate that this finding was contributed to most importantly by the greater maximal doses achieved during GKS, which have in the past been shown to correlate with delayed radiation injury.

Rates of hemorrhage were not included in our analysis, three having occurred in the LINAC group and one in the GKS group, but are compatible with recent literature.

We recognize the limitations of this study, which include its retrospective design; the small number of patients exhibiting symptomatic edema precluding a multivariate analysis of all variables; and the heterogeneity of the patient population with regards to pre-radiosurgical treatment and treatment modality. We also recognize that the treatments were performed at different hospitals and that our institution has had a longer experience with the use of LINAC than GKS. ${ }^{40}$ Therefore, the results have to be interpreted with caution.

\section{ACKNOWLEDGEMENT}

The authors thank Dr. Sapna Rawal for her contributions to the statistical analysis and editing of the paper.

\section{REFERENCES}

1. Friedlander RM. Arteriovenous malformations of the brain. N Engl J Med. 2007;356(26):2704-12.

2. Gross BA, Du R. Natural history of cerebral arteriovenous malformations: a meta-analysis. J Neurosurg. 2013;118(2): 437-43.

3. Lim M, Cheshier S, Steinberg GK. New vessel formation in the central nervous system during tumor growth, vascular malformations, and moyamoya. Curr Neurovasc Res. 2006;3(3): 237-45.

4. Sure U, Butz N, Schlegel J, et al. Endothelial proliferation, neoangiogenesis, and potential de novo generation of cerebrovascular malformations. J Neurosurg. 2001;94(6):972-7.

5. Pollock BE, Gorman DA, Coffey RJ. Patient outcomes after arteriovenous malformation radiosurgical management: results based on a 5- to 14-year follow-up study. Neurosurgery. 2003;52 (6):1291-7.

6. Pollock BE, Flickinger JC. A proposed radiosurgery-based grading system for arteriovenous malformations. J Neurosurg. 2002;96 (1):79-85.

7. Andrade-Souza YM, Zadeh G, Ramani M, Scora D, Tsao MN, Schwartz ML. Testing the radiosurgery-based arteriovenous malformation score and the modified spetzler-martin grading system to predict radiosurgical outcome. J Neurosurg. 2005;103 (4):642-8.

8. Pollock BE, Flickinger JC. Modification of the radiosurgery-based arteriovenous malformation grading system. Neurosurgery. 2008;63(2):239-43.

9. Pollock BE, Flickinger JC. A proposed radiosurgery-based grading system for arteriovenous malformations. J Neurosurg. 2002;96 (1):79-85.

10. Flickinger JC, Kondziolka D, Lunsford LD, et al. Development of a model to predict permanent symptomatic postradiosurgery injury for arteriovenous malformation patients. Arteriovenous malformation radiosurgery study group. Int J Radiat Oncol Biol Phys. 2000;46(5):1143-8.

11. Flickinger JC, Kondziolka D, Lunsford LD, et al. A multiinstitutional analysis of complication outcomes after arteriovenous malformation radiosurgery. Int J Radiat Oncol Biol Phys. 1999;44(1):67-74. 
12. Flickinger JC, Lunsford LD, Kondziolka D, et al. Radiosurgery and brain tolerance: an analysis of neurodiagnostic imaging changes after gamma knife radiosurgery for arteriovenous malformations. Int J Radiat Oncol Biol Phys. 1992;23(1):19-26.

13. Lee J, Girvigian M, Miller M, et al. Validation of a radiosurgerybased grading system for arteriovenous malformations. In: Kondziolka D, editor. Radiosurgery. Basel: Karger; 2006: 221-8.

14. Cohen-Gadol AA, Pollock BE. Radiosurgery for arteriovenous malformations in children. J Neurosurg. 2006;104(6 Suppl): 388-91.

15. Moreno-Jimenez S, Celis M, Larraga-Gutierrez J, et al. Intracranial arteriovenous malformations treated with LINAC-based conformal radiosurgery: validation of the radiosurgery-based arteriovenous malformation score as a predictor of outcome. Neurol Res. 2007;29(7):712-16.

16. Flickinger J, Kondziolka D, Kalend A, Maitz A, Lunsford L. Radiosurgery-related imaging changes in surrounding brain: Multivariate analysis and model evaluation. In: Kondziolka D, editor. Radiosurgery 1995. Switzerland: Kargel; 1996. p 229.

17. Flickinger JC, Kondziolka D, Maitz AH, Lunsford LD. Analysis of neurological sequelae from radiosurgery of arteriovenous malformations: how location affects outcome. Int J Radiat Oncol Biol Phys. 1998;40(2):273-8

18. Flickinger JC. An integrated logistic formula for prediction of complications from radiosurgery. Int J Radiat Oncol Biol Phys. 1989;17(4):879-85.

19. Sirin S, Kondziolka D, Niranjan A, Flickinger JC, Maitz AH, Lunsford LD. Prospective staged volume radiosurgery for large arteriovenous malformations: indications and outcomes in otherwise untreatable patients. Neurosurgery. 2006;58(1):17-27.

20. Sun DQ, Carson KA, Raza SM, et al. The radiosurgical treatment of arteriovenous malformations: obliteration, morbidities, and performance status. Int J Radiat Oncol Biol Phys. 2011;80(2): 354-61.

21. Nataf F, Ghossoub M, Missir O, et al. Parenchymal changes after radiosurgery of cerebral arteriovenous malformations. clinical and MRI data. Neurochirurgie. 2001;47(2-3 Pt 2):355-68.

22. Levegrun S, Hof H, Essig M, Schlegel W, Debus J. Radiationinduced changes of brain tissue after radiosurgery in patients with arteriovenous malformations: correlation with dose distribution parameters. Int J Radiat Oncol Biol Phys. 2004;59 (3):796-808.

23. Douglas JG, Goodkin R. Treatment of arteriovenous malformations using gamma knife surgery: the experience at the University of Washington from 2000 to 2005. J Neurosurg. 2008;109 Suppl:51-6.

24. Hayhurst C, Monsalves E, van Prooijen M, et al. Pretreatment predictors of adverse radiation effects after radiosurgery for arteriovenous malformation. Int J Radiat Oncol Biol Phys. 2012; 82(2):803-8.

25. Friedman WA, Bova FJ, Bollampally S, Bradshaw P. Analysis of factors predictive of success or complications in arteriovenous malformation radiosurgery. Neurosurgery. 2003;52(2):296-307; discussion 307-8.
26. Pollock BE. Occlusive hyperemia: a radiosurgical phenomenon? Neurosurgery. 2000;47(5):1178-82; discussion 1182-4.

27. Santos ML, Demartini Júnior Z, Matos LA, et al. Angioarchitecture and clinical presentation of brain arteriovenous malformations. Arq Neuropsiquiatr. 2009;67(2A):316-21.

28. Taeshineetanakul P, Krings T, Geibprasert S, et al. Angioarchitecture determines obliteration rate following radiosurgery in brain arteriovenous malformations. Neurosurgery. 2012;71 (6):1071-8

29. van den Berg R, Buis DR, Lagerwaard FJ, Lycklama à Nijeholt GJ, Vandertop WP. Extensive white matter changes after stereotactic radiosurgery for brain arteriovenous malformations: a prognostic sign for obliteration? Neurosurgery. 2008;63(6): 1064-9; discussion 1069-70.

30. Lv X, Li Y, Yang X, Jiang C, Wu Z. Characteristics of brain arteriovenous malformations in patients presenting with nonhemorrhagic neurologic deficits. World Neurosurg. 2012;79 (3-4):484-8.

31. Orio P, Stelzer KJ, Goodkin R, Douglas JG. Treatment of arteriovenous malformations with linear accelerator-based radiosurgery compared with gamma knife surgery. J Neurosurg. 2006;105 Suppl:58-63.

32. Izawa M, Hayashi $\mathrm{M}$, Chernov $\mathrm{M}$, et al. Long-term complications after gamma knife surgery for arteriovenous malformations. J Neurosurg. 2005;102 Suppl:34-7.

33. Raffa SJ, Chi Y, Bova FJ, Friedman WA. Validation of the radiosurgery-based arteriovenous malformation score in a large linear accelerator radiosurgery experience. J Neurosurg. 2009; 111(4):832-9.

34. Karlsson B, Lax I, Soderman M. Factors influencing the risk for complications following gamma knife radiosurgery of cerebral arteriovenous malformations. Radiother Oncol. 1997;43(3): 275-80.

35. Kader A, Young WL, Pile-Spellman J, et al. The influence of hemodynamic and anatomic factors on hemorrhage from cerebral arteriovenous malformations. Neurosurgery. 1994;34 (5):801-7; discussion 807-8.

36. Spetzler RF, Hargraves RW, McCormick PW, Zabramski JM, Flom RA, Zimmerman RS. Relationship of perfusion pressure and size to risk of hemorrhage from arteriovenous malformations. J Neurosurg. 1992;76(6):918-23.

37. Stefani MA, Porter PJ, terBrugge KG, Montanera W, Willinsky RA, Wallace MC. Angioarchitectural factors present in brain arteriovenous malformations associated with hemorrhagic presentation. Stroke. 2002;33(4):920-4.

38. Hollerhage HG. Venous drainage system and risk of hemorrhage from AVM's. J Neurosurg. 1992;77(4):652-4.

39. Kim BS, Sarma D, Lee SK, terBrugge KG. Brain edema associated with unruptured brain arteriovenous malformations. Neuroradiology. 2009;51(5):327-35

40. Young C, Summerfield R, Schwartz M, O’Brien P, Ramani R. Radiosurgery for arteriovenous malformations: the University of Toronto experience. Can J Neurol Sci. 1997;24(2):99-105. 